Bond University

Research Repository

\title{
Criminal and Noncriminal Psychopathy: The Devil is in the Detail
}

\author{
Brooks, Nathan; Fritzon, Katarina; Watt, Bruce D.; Duncan, Keith; Madsen, Lars \\ Published in: \\ Corporate Psychopathy: Investigating Destructive Personalities in the Workplace
}

DOI:

10.1007/978-3-030-27188-6_3

Licence:

Other

Link to output in Bond University research repository.

Recommended citation(APA):

Brooks, N., Fritzon, K., Watt, B. D., Duncan, K., \& Madsen, L. (2020). Criminal and Noncriminal Psychopathy: The Devil is in the Detail. In K. Fritzon, N. Brooks, \& S. Croom (Eds.), Corporate Psychopathy: Investigating Destructive Personalities in the Workplace (pp. 79-105). Palgrave Macmillan. https://doi.org/10.1007/978-3-03027188-6_3

\section{General rights}

Copyright and moral rights for the publications made accessible in the public portal are retained by the authors and/or other copyright owners and it is a condition of accessing publications that users recognise and abide by the legal requirements associated with these rights.

For more information, or if you believe that this document breaches copyright, please contact the Bond University research repository coordinator. 


\title{
Chapter 3
}

\section{Criminal and Noncriminal Psychopathy - The Devil is in the Detail Nathan Brooks, Katarina Fritzon, Bruce Watt, Keith Duncan, Lars Madsen}

\begin{abstract}
Psychopathy is prevalent and problematic in criminal populations, but is also found to be present in non-criminal populations. In 1992, Robert Hare declared that psychopaths may also "be found in the boardroom", which has since been followed by an interest in the issue of non-criminal, or even successful, psychopathy. In this chapter the paradox of criminal and noncriminal psychopathy is discussed with specific attention given to the similarities and differences that account for psychopathic personality across contexts. That psychopathy is a condition typified by a constellation of traits and behaviours requires wider research across diverse populations, and thus the streams of research related to criminal and non-criminal psychopathy are presented and the implications of these contrasting streams are explored.
\end{abstract}

\section{Understanding the Details}

Research and case presentations have observed vast variation in psychopathic personality, from high performing executives to violent offenders (Babiak, 1995; Brooks, 2017; Cleckley, 1941, 1976; Dutton, 2012; Hare, 2003). Conceptualisations of psychopathy should consider how psychopathic personality traits may vary across contexts and settings, accounting for both the similarities and differences. Criminal and noncriminal psychopathy are considered as similar, yet possibly etiologically distinct constructs (Hall \& Benning, 2006; Polaschek, 2015; Skeem et al., 2011). Psychopathy, regardless of whether criminal or noncriminal manifestation, is a pervasive psychological disorder characterised by a lack of conscience (Cleckley, 1941, 1976; Hare, 1999). Successful or corporate psychopathy may describe individuals with high levels of education and personality traits that have allowed them to achieve corporate status (Boddy, 2011; Gao \& Raine, 2010), while criminal psychopathy may be associated with lower socio-economic support and a tendency towards impulsivity (Hare, 2003; Skeem et al., 2011). Psychopathic criminals are 
typically described as cunning and manipulative, calculated, violent and reckless in nature, callous, and prone to heinous and repetitive acts of crime (Hare, 1999a, 2003; Stone, 2009). In contrast, individuals with psychopathic traits residing in the community are proposed to be successful and capable of functioning in society, despite being ruthless, immoral, manipulative, charming, grandiose and lacking concern for others (Babiak \& Hare, 2006; Boddy, 2011; Dutton, 2012; McNab \& Dutton, 2014). This chapter will examine criminal and noncriminal psychopathy, exploring research findings, similarities and discrepancies across trait presentations, and discuss implications for future investigation of psychopathic personality in specific populations.

\section{Criminal Psychopathy}

Research that has examined psychopathy in offender populations has found that psychopathy is associated with several factors related to criminality (Cornell et al., 1996; Hare, 1999, 2003; Hare \& McPherson, 1984). The desire to control and dominate another has been identified as a central trait of psychopathic personality, often engaging in threats, bullying, verbal intimidation, manipulation, and physical aggression to achieve such outcomes (Hickey, 2010; Hare, 1999). Individuals with psychopathic traits in comparison to non-psychopathic offenders, have been found to utilise greater levels of violence and aggression, use a weapon or commit a violent assault, engage in aggressive behaviour in the custodial setting (Hare \& McPherson, 1984), perpetrate planned and instrumental acts of violence (Cornell et al., 1996; Woodworth \& Porter, 2002), possess cognitions supporting violence and aggression (Watt \& Brooks, 2012), and engage in behaviours that threaten and challenge those perceived to be blocking the pursuit of goals (Morrison \& Gilbert, 2001). The drive to dominate others and obtain self-indulgent goals, even when at a cost to another, is the cornerstone of psychopathy (Meloy, 2005; Meloy \& Shiva, 2007).

There has been body of work examining psychopathy in criminal settings, with findings indicating that psychopathic offenders are more likely to commit violent crimes for instrumental reasons and are at a greater likelihood of reoffending upon release from custody (Cornell et al., 1996; Hare, 2003; Porter, Birt, \& Boer, 2001; Serin \& Amos, 1995; Woodworth \& Porter, 2002). Psychopathy as measured by the PCL-R and its derivate tools, is commonly found to show moderate associations with 
most forms of crime and future violence (Douglas, Vincient, \& Edens, 2018). For example, offenders with psychopathic personality were found to be five times more likely to engage in violent recidivism within five years of release from incarceration (Serin \& Amos, 1995) and to consistently perpetrate more violent and non-violent crimes than their non-psychopathic counterparts (Porter et al., 2001). However, one the major concerns regarding psychopathy is that the construct has become associated with representing recidivism, particularly for violence (Polaschek, 2015). This is troubling as the PCL-R was designed to measure a personality construct, rather than to predict crime or violence (Douglas et al., 2018). As Polaschek (2015) states, "criminals are neither inevitably psychopathic, nor are psychopaths inevitably criminal' (p. 2). A psychopathy assessment therefore is not representative of risk and should only be a guiding factor that is considered alongside evidence based-risk assessments. Alone, the PCL-R should never be used to make risk decisions, requiring accompanying risk assessment protocols (Douglas et al., 2018). While research has demonstrated a relationship between psychopathy and criminality, this does not suggest that crime or violence is a core characteristic of psychopathy, but rather one of many secondary consequences related to the personality construct (Lilienfeld \& Widows, 2005; Polaschek, 2015).

One of the most commonly observed associations in regard to psychopathy and offending behaviour, concerns violent offending (Hare, 1999; Hare \& McPherson, 1984; Stone, 2001). Logan and Hare (2008) estimate that up to $90 \%$ of serial killers would meet the PCL-R criteria to be classified as psychopathic. Notably, in a study of 99 serial sexual murders, Stone (2001) found the $91 \%$ of the sample scored 30 or greater on the PCL-R, however, one of the primary criticisms of this finding was the reliance on biographical information to assess the psychopathy traits of the serial offenders (Hickey, Walters, Drislane, Palumbo, \& Patrick, 2018).

It is not uncommon for serial murders to be considered as displaying psychopathy characteristics due to the brutal nature of their offending and the process by which crimes are committed, such as through torture, rape, necrophilia and cannibalism (Hickey et al., 2018). However, despite committing heinous acts violence, many serial murders only display features of psychopathic personality, rather than pervasive levels of the personality. Although there is often evidence of callousness and coldheartedness in the crimes of serial killers, it is unclear to what 
extent these individuals exhibit boldness-fearlessness and impulsivity-disinhibition features (Patrick, Fowles, \& Krueger, 2009). For example, based on cases being rated by trained diagnosticians using the PCL-R, Hickey and colleagues (2018) assessed Theodore Bundy (Total $=34$, Factor $1=16$, Factor $2=15.5)$, John Wayne Gacy $($ Total $=27$, Factor $1=16$, Factor $2=9)$, Edmund Kemper $($ Total $=26$, Factor $1=13$, Factor $2=11)$, Jeffrey Dahmer (Total $=23$, Factor $1=9$, Factor $2=12$ ), and Gary Ridgeway $($ Total $=19$, Factor $1=11$, Factor $2=4.5)$. Contrary to the view that most serial murders are clinically psychopathic, the author's found that only one of the five cases, Theodore (Ted) Bundy, was endorsed as exceeding the PCL-R diagnostic scores.

A common misconception concerning psychopathy is that an isolated event, such as a violent murder, is attributed to be representative of psychopathic personality. As Hare (2003) notes, psychopathy is characterised by life-coursepersistent traits and behaviours. One the main challenges of determining the relationship between psychopathy and repeated offending is that serial murder is a rare occurrence, with limited subjects available for examination, and some offenders apprehended for single acts of violence despite having suspected repeated victims (Hickey et al., 2018). Moreover, it is unknown whether serial murders who evade detection (such as the Zodiac Killer who operated in California in the 1960's and 1970's) for their serial offending display different personality features possibly associated with their ability to avoid detection. Whether offending is committed by a serial offender or perpetrated as a singular act, it appears that the disinhibitory characteristics (such as substance use, deviancy, paraphilias, and impulsivity) may be greater predictors of violence than the totality of psychopathic personality (Hickey et al., 2018; Polaschek, 2015)

One of the features considered to be associated with psychopathy and crime, is the tendency for psychopathic individuals to be impulsive and violent. Interestingly, despite impulsivity being considered a core feature of psychopathy, research has consistently found that in psychopathic offenders, instrumental offending is evident, commonly characterised by premeditation and the desire to achieve an external goal. Woodworth and Porter (2002) investigated the association between psychopathy and instrumental violence in a sample of homicide perpetrators. The authors found that 93.3\% of the homicides committed by psychopathic offenders were instrumentally 
motivated, compared to non-psychopathic individuals who were less likely to perpetrate homicide for instrumental reasons (48.4\%). The findings were in contrast to the notion that psychopathic individuals are highly spontaneous and impulsive, something which the authors attributed to 'selective impulsivity'. According to Woodworth and Porter, psychopathic people may behave in a more instrumental manner based on the gravity or seriousness of an event or situation, planning their actions in a calculating manner when the stakes are high (e.g., perpetrating an act of homicide, which has the consequences of lifetime incarceration). The findings by Woodworth and Porter (2002) highlight that psychopathic offending can be instrumental in nature; however, the tendency to towards 'selectivity impulsivity' may also vary as a function of disinhibition (Polaschek, 2015). It is possible that general impulsivity is related to higher levels of disinhibition, but in cases where fewer traits of disinhibition are apparent and coupled with affective deficits, instrumental offending may emerge.

The empathy and emotional deficits associated with psychopathy may also serve to explain the relationship between psychopathic personality and offending behaviour (Blair et al., 2005; Hare \& Quinn, 1971; Williamson et al., 1991). Early literature on psychopathy focused on the study of criminal samples and identified that offenders with high levels of psychopathy demonstrated a profound lack of empathic concern for others, as well as difficulties recognising and responding to emotions (Blair et al., 1997; Cleckley, 1941, 1976; Hare \& Quinn, 1971; Johns \& Quays, 1962; Lykken, 1957; Williamson et al., 1991). This early research often concluded that criminal and antisocial behaviour was partially due to the empathy deficits associated with psychopathy. Research on the construct has seen a wide range of studies examining psychopathy, empathy and criminality. For example, Brook and Kosson (2013) observed that psychopathic offenders had lower levels of empathic accuracy in comparison to non-psychopathic offenders after controlling for intelligence, reading ability and perceived emotional intelligence. While the relationship between the PCL$\mathrm{R}$ factors and the subscales of the IRI were not reported in the research (other than perspective taking), the research suggested that cognitive empathy deficits were most notable for the antisocial/behavioural and lifestyle features of psychopathy.

Despite an established relationship between low empathy and psychopathy, interesting research has been noted when reviewing the construct of empathy, 
shedding light on the potential functionality of psychopathic personality. Using the PCL-R and MRI evaluations to examine psychopathy, Decety et al. (2013) examined the neurological responses of 121 offenders. Subjects were required to view stimuli of body injuries and requested to adopt imagine-self and imagine-other perspectives (Decety et al., 2013). When presented with stimuli and adopting an imagine-self perspective, the high psychopathy group demonstrated typical neurological patterns of response for the brain regions involved in empathy for pain, however, an atypical pattern of brain activation was observed for the psychopathic group when adopting the imagine-other perspective (Decety et al., 2013). The atypical pattern of neural activation for the imagine-other perspective was significantly different for offenders with elevated scores on factor one of the PCL-R, indicating a reduced arousal to others' pain or concerns (Hare, 2003; Hare \& Quinn, 1971). Elevated scores on factor one were found to be associated with an increase in activity in the ventral striatum, suggesting pleasure in observing the distress of others. This pattern of activation in the ventral striatum, which is typically activated during reward anticipation (Diekhof, Kaps, Falkai, \& Gruber, 2012), was only found for elevations on factor one, and not factor two. The findings of the research suggested that offenders with high levels of psychopathy were capable of imagine-self perspective taking abilities, however, were characterised by marked deficits in imagine-other perspective taking (Decety et al., 2013). The research provided an important understanding of the perspective taking element of empathy in offenders and raised the questions as to whether perspective taking plays a central role in noncriminal or successful psychopathy.

The finding by Decety et al. (2013) suggested that factor one of the PCL-R was associated with perspective taking deficits, however, high scores on factor two may not lead to lower levels of perspective taking. Mullins-Nelson et al. (2006) contend that the relationship between psychopathy and empathy depends largely on the type of psychopathy evaluated (e.g., factor or total score), gender of the individual, as well at the population being examined. For example, general levels of empathy may be lower in custodial settings rather than in the community. While higher overall scores on the PCL-R for some offenders may be largely due to a greater propensity of lifestyle and antisocial traits, rather than interpersonal and affective features, therefore, resulting in an elevated PCL-R score. Consequently, the interpersonal and affective traits, often identified as the core personality 
characteristics of psychopathy (Brook \& Kosson, 2013), may not be solely representative of criminal samples, instead an important feature in noncriminal samples where lifestyle and antisocial traits may be less common (Hall \& Benning, 2006; Mullins-Nelson et al., 2006).

Like empathy, the relationship between psychopathy and manipulation has important implications for understanding psychopathy across populations. For example, Porter et al. (2009) found that psychopathic offenders, while having a greater history of criminal offending, were two and half times more likely to be granted conditional release than non-psychopathic offenders. Similar findings were reported by Häkkänen-Nyholm and Hare (2009) in a study of 546 Finnish homicide offenders. The authors examined psychopathy and post offence behaviour for homicide cases. The researchers conducted a case file review and assessed psychopathy retrospectively on the PCL-R. Eighteen percent of the sample was identified as having a score of 30 or more on the PCL-R. Notably, one third of offenders sampled achieved the maximum score on the PCL-R item pathological lying (Häkkänen-Nyholm \& Hare, 2009). Due to the seriousness of their offence, individuals with higher levels of psychopathy were referred to higher levels of court, however, were paradoxically more likely to be convicted of a lesser offence. High levels of psychopathic traits were also related to reduced levels of remorse, placing blame on external factors for the offence, and denial of responsibility for actions. When the stakes are high, psychopathic people demonstrate a sound ability to manipulate and deceive others. Despite high level processes in place to mitigate deception and manipulation in the criminal justice system, psychopathic individuals are successfully able to overcome obstacles, raising questions regarding what could be achieved in the community where both awareness and barriers are considerably lower. Moreover, in cases where psychopathic individuals have lower levels of disinhibition, greater social adjustment, generally positive upbringings and receive higher levels of education, notably different life trajectories may emerge. According to Benning, Venables, and Hall (2018), there are multiple pathways to the development of psychopathy, with personality features moderated by life events, exposing some individuals to factors associated with criminality, while for others positive socialisation may lead to integration within the community. 


\section{Noncriminal and Successful Psychopathy}

It is an unusual phenomenon that a personality type found to be associated with destructive and criminal behaviour is also related to levels of success and achievement (Babiak \& Hare, 2006; Boddy, 2011; Brooks, 2017; Fritzon et al., 2016). The corporate and business sector is a vast contrast to the custodial environment, requiring levels of social and interpersonal skills, responsibility, education, and performance standards (Benning et al., 2018; Boddy, 2011, 2015; Perri, 2013). Yet, despite skill and educational demands, research has identified several successful individuals that have elevated levels of psychopathic traits (Babiak et al., 2010; Brooks, 2017; Fritzon et al., 2016). These include, USA presidents (Lilienfeld et al., 2012), high court justices, city mayors, academic deans (Mullins-Sweatt et al., 2010; Stevens, Deuling, \& Armenakis, 2012), corporate executives and directors (Babiak et al., 2010), a leading neuroscientist (Fallon, 2014), and a decorated special forces officer (Dutton, 2012; McNab \& Dutton, 2014).

Ishikawa, Raine, Lencz, Bihrle, and LaCasse (2001) examined the concept of successful and unsuccessful psychopathy. The authors examined psychopathy in the community and determined success based on whether participants had ever been convicted of a crime. Psychopathy was assessed on the PCL-R and participants completed the Wisconsin Card Sorting Test (WCST) and the Weschler Memory Scale-Revised (WMS-R). The successful psychopathy group comprised of 13 participants (never convicted of a crime), unsuccessful psychopathy group of 16 participants (convicted of a crime) and the control comparison group of 26 nonpsychopathic (low scoring psychopathy and never convicted of a crime) participants. Results revealed that successful psychopathy was associated with greater executive functioning on the WCST and an elevated heart rate for stress reactivity in comparison to unsuccessful psychopathy and control groups (Ishikawa et al., 2001). The unsuccessful psychopathy group were found to have a lower heart rate and reduced executive functioning compared to the successful psychopathy and nonpsychopathy groups. No difference was found between the two psychopathy groups for intelligence. The authors concluded that the elevated autonomic responding and greater executive functioning displayed by the successful psychopathy group served to protect from detection and arrest in the community, responsive to cues and consequences (Ishikawa et al., 2001). The research provided an important comparison 
of criminal and noncriminal psychopathy for stress reactivity and executive functioning, however, the study did not include a comparison group of unsuccessful non-psychopathy participants, or account for social and emotional skills which may further serve to protect from detection and arrest.

A similar study investigating intelligence, executive functioning, empathy and psychopathy was conducted by Mahmut et al. (2008). The study comprised of 27 males and 74 females recruited from a university sample. The measures used in the research included the SRP-III (Paulhus et al., in press), Iowa Gambling Task (IGT; Bechara, Damásio, Damásio, \& Anderson, 1994), the Emotional Empathy Questionnaire (EEQ; Mehrabian \& Epstein, 1972), National Adult Reading Test (NART; Nelson, 1991), and Trail-Making Test-Part B (TMT-B; Reitan, 1992). The authors dichotomised the data into high and low psychopathy groups based on the highest $30 \%$ and lowest $30 \%$ of scores on the SRP-III. The SPR-III subscale of criminal tendencies was excluded from the analyses to avoid conflating psychopathy with antisocial behaviour (Mahmut et al., 2008). Results found that the high psychopathy group performed significantly poorer on the IGT in comparison to the low psychopathy group, making riskier choices and concluding the game with less money. A significant deficit in emotional empathy was found for the high psychopathy group, although the deficit in emotional empathy was not observed for the low psychopathy group. No significant difference was found between the psychopathy groups for IQ or executive functioning based on the NART and TMT-B.

Mahmut et al. (2008) compared the results to a previous study (Mitchell, Colledge, Leonard, \& Blair, 2002) that had employed the IGT with a criminal sample, concluding that findings from the two studies were similar and that criminal and noncriminal psychopathy are qualitatively similar, sharing psychophysiological and neurophysiological characteristics. The researchers contended that the manifestation of interpersonal and affective traits, as well as the extent to which individuals engaged in antisocial behaviours, may be the only differentiating features between criminal and noncriminal psychopathy (Mahmut et al., 2008). Due to the challenges of contrasting psychopathy across populations, the authors recommended that future research employ the same measurement protocols across populations to control for measurement variance and to allow for consistent comparison. The notable limitations of the research were that the study comprised predominately of females and that the 
authors dichotomised psychopathy rather than examined the construct on a continuum, excluding a large percentage of the sample from the analyses.

Another study examining noncriminal psychopathy, emotional intelligence, and criminal thinking was conducted by Fix and Fix (2015) utilising a sample of 111 university students. The authors employed the PPI-R (Lilienfeld \& Widows, 2005) to examine psychopathy, Bar-On EQ-i (EQ-i; Bar-On, 2008) to measure emotional intelligence, Inventory of Callous-Unemotional Traits-Youth Version (ICU; Frick, 2006) to assess callousness, Texas Christian University Criminal Thinking Scales (TCU; Knight, Garner, Simpson, Morey, \& Flynn, 2006), and Illegal Behaviours Checklist (IBC; McCoy et al., 2006). Despite the sample being community based, psychopathy was found to be a significant predictor of violent offending, property offending and illegal behaviour. Regression analyses showed that psychopathy was predicted by lower interpersonal and mood scores, and higher scores on stress management and interpersonal relationships. Higher scores on the uncaring subscale of the ICU also significantly predicted psychopathy. Fix and Fix (2015) contended that the results provided a portrait of successful psychopathy, characterised by interpersonal skills, but lacking in empathy and social responsibility, displaying little concern for others, troubled by understanding emotions and holding a pessimistic emotional outlook, although fluid in managing levels of stress (Fix \& Fix, 2015). The findings by the authors demonstrated that psychopathy was characterised by positive adaptive features such as stress management, yet also significantly predicted criminal behaviour, supporting research on psychopathy and stress immunity (Fowles \& Dindo, 2009; Lilienfeld \& Widows, 2005; Lykken, 1995; Patrick et al., 2009) and suggesting that successful psychopathy may be associated with avoiding detection.

Howe et al. (2014) investigated the relationship between psychopathic personality traits, emotional intelligence and success in 55 participants working in the financial industry in New York. The authors used the PPI-R, the Mayer-SaloveyCaruso Emotional Intelligence Test (MSCEIT; Mayer, Salovey \& Caruso, 2002) and a series of demographic questions to assess income and position within the company. The results of the study revealed that $7.3 \%$ of the sample were found to score two standard deviations above the normative mean score for the PPI-R. Significant elevations above the clinical cut off $T$ score were observed for fearless dominance (12.7\%) and coldheartedness (9.1\%); however, no notable elevated levels of self- 
centred impulsivity were found in the sample. Total PPI-R scores were negatively related to overall emotional intelligence as well as subscales of the MSCEIT. A significant negative relationship was found for self-centred impulsivity and total MSCEIT scores, although no significant associations were found between fearless dominance and total or subscale MSCEIT scores. Statistical analysis of income groups revealed that significant differences were only identified for fearless dominance, with no differences found for total PPI-R scores or remaining subscales. Fearless dominance was found to significantly predict the income bracket of $\$ 100,000$ to $\$ 200,000$, with higher scores found for this level of income compared to the less than 100,000 and over $\$ 200,000$ groups (Howe et al., 2014). No significant differences were observed for total psychopathy or subscales for corporate rank. The authors postulated that the interpersonal-affective features of psychopathy may help an individual to obtain a moderate level of success, however, they suggested that an optimal level of psychopathic traits may exist and that exceeding this level could have a detrimental effect on career success.

\section{What does it all mean?}

It is evident that psychopathic traits exist in criminal, noncriminal and business populations. Hare $(1999,2003)$ contends that regardless of the setting, psychopathic personality is comprised of interpersonal, affective, lifestyle, and antisocial features. However, emerging research suggests that psychopathic traits may cluster to form specific typologies, including criminal, noncriminal, and successful psychopathy, each characterised by a specific constellation of psychopathic characteristics, with a dominant phenotypic pattern often evident (Dutton, 2012; Hall \& Benning, 2006; Skeem et al., 2011). These differences in psychopathy typologies are marked through etiological pathways, temperament, motivation, and social and emotional expression (Costa \& McCrae, 2003; Fowles \& Dindo, 2009; Hall \& Benning, 2006; Millon \& Davis, 1998; Willemsen \& Verhaeghe, 2012). For example, research suggests that the interpersonal and affective features of psychopathy are negatively associated with fear and anxiety, while the behavioural traits are positively related to fear and anxiety (Willemsen \& Verhaeghe, 2012). Considering the three distinct but intersecting constructs of the triarchic model (Patrick et al., 2009), a 
greater unique contribution of boldness, and reduced features of disinhibition may explain noncriminal and successful psychopathy

The unique role of fearless dominance/boldness/interpersonal-affective features and the self-centred impulsivity/disinhibition/lifestyle-antisocial characteristics in distinguishing subtypes of psychopathy has been the centrepiece of much debate amongst leading experts (Hall et al., 2014; Lilienfeld et al., 2012; Poythress et al., 2010; Skeem et al., 2011). Notably, psychopathy is a paradoxical disorder, with individuals appearing high functioning and interpersonally skilled, yet marked by emotional and cognitive processing deficits (Cleckley, 1988, Lilienfeld et al., 2012; Lykken, 1995). In his pioneering work Cleckley $(1941,1976)$ described psychopathic people as charming, fearless and bold, interpersonally dominant, with intact intelligence and low anxiety, yet reckless and dishonest. The Cleckley depiction of psychopathy was characterised by a prominent pattern of interpersonal and affective features, with traits of disinhibition that were not necessarily marked by violence. In contrast, Hare $(1999,2003)$ describes psychopathy as characterised by shared interpersonal, affective, lifestyle and antisocial features. Hare's conceptualisation of the psychopathic individual is of a callous, impulsive, egocentric, hostile, and ruthless person, characterised by self-centred behaviour, poor interpersonal relationships, destructive actions and criminality. Sharing somewhat similar views to both Cleckley and Hare, Lykken $(1957,1995)$ and Karpman (1941, 1948) detailed primary and secondary psychopathy, which were characterised by differences in emotionality and psychopathy trait patterns. The emergence of recent research investigating noncriminal psychopathy has proposed that psychopathy is characterised by positive adaptive features, suggesting that the right constellation of psychopathic traits could lead to success in the community (Broad \& Fritzon, 2005; Dutton, 2012; Howe et al., 2014).

Cleckley $(1941,1976)$ and Hare's $(2003)$ conceptualizations of psychopathy are markedly different; yet, these differences may be a result of how their formulations of psychopathy were determined, with both experts conducting research on vastly different populations. Cleckley's assessment of psychopathy was largely determined based on his work with patients in a Georgia psychiatric facility, as well as community based patients. Hare's work has been predominately based on North American offenders, with the origins of his PCL-R based on criminals. Recent work 
on psychopathy in the corporate and business sectors has examined the notion that psychopathy can be related to success and has adaptive features. For example, psychologist Kevin Dutton (2012) determined former decorated SAS soldier Andy $\mathrm{McNabb}$ to be psychopathic based on neuropsychological testing. Dutton contends that certain trait qualities associated with psychopathy can lead to success and functioning in the community. Consequently, the debate regarding psychopathy traits appears to depend on who is being assessed, where the assessment is occurring, and what assessment protocol is used to measure psychopathy.

Due to variations in assessment methodologies and samples, consensus is yet to be reached in establishing baseline prevalence rates of psychopathy in business settings. For example, the occurrence of psychopathic personality in corporate settings has been suggested to range between 4\% and 20\% (Babiak et al., 2010; Fritzon et al., 2016; Howe et al., 2014). These figures, while higher than the approximate one percent found in the general community (Hare, 1999), fall in between the community base rate and the level of psychopathy identified in offender populations (15 to 25 percent; Hart \& Hare, 1996). Understanding the prevalence of psychopathy across populations is an important starting point when attempting to contrast and draw conclusions about the construct in business settings. One of the main challenges to comparing findings on psychopathic personality across studies is that research often reports overall scores and fails to provide a descriptive overview of subscales and score dispersions, making it difficult to determine the overall distribution of psychopathic traits in a study, along with identifying the prominent personality factors associated with the sample (Benning et al., 2018). Interestingly, a recent study has provided some insight into the comparison of psychopathic traits across populations by employing the same methodology across samples. Using the PPI-R to assess psychopathy, Brooks (2017) contrasted psychopathic personality traits in noncriminal (community), business and criminal samples. Based on a $T$ score of 65 , consistent with one and a half standard deviations above the mean score, all samples were identified to have individuals with clinically significant levels of psychopathy.

The noncriminal sample had 21 (18.3\%) participants with clinically elevated levels of psychopathy, while 94 (81.7\%) were without elevations. In the business sample, seven (11.67\%) participants were found to have clinical levels of 
psychopathy, while 53 participants did not. For the criminal sample, four participants $(9.1 \%)$ were found to have clinically elevated levels of psychopathy, while 40 participants did not have clinically elevated levels. The distribution of the percentage of clinically elevated psychopathy traits for the business, criminal and noncriminal samples can be seen below.

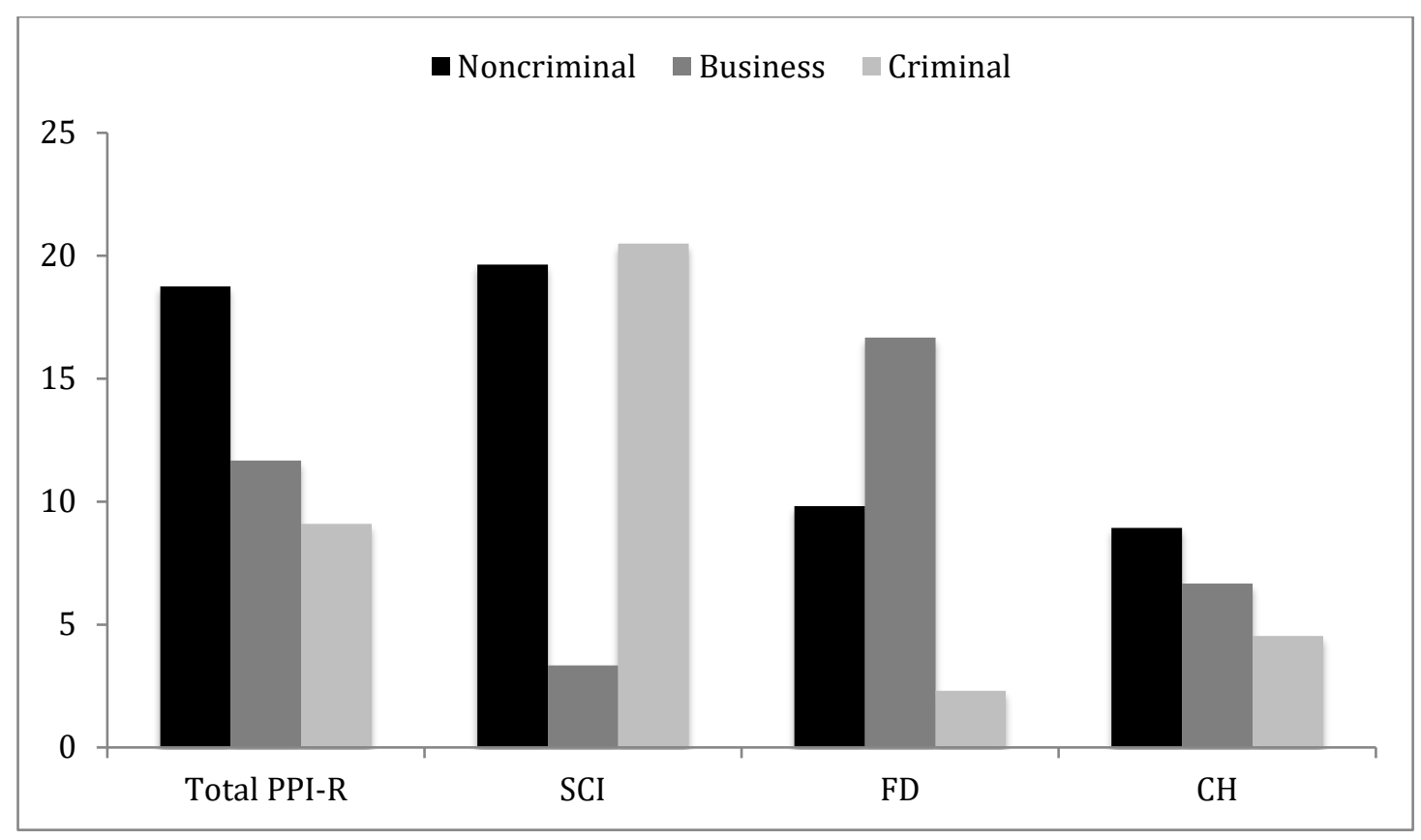

Figure 3.1. The percentage of clinically elevated levels of the total psychopathy, self-centred impulsivity, fearless dominance and coldheartedness in the noncriminal, business and criminal samples.

Further investigation of results in the study, which were examined through regression analysis, revealed that higher levels of fearless dominance was found in the business sample compared to the noncriminal and criminal samples. Brooks (2017) concluded that this finding provided support for the dual pathways model of psychopathy (Benning et al., 2018; Hall \& Benning, 2006), as well as the depiction of primary psychopathy as described by Lykken (1995), and Cleckley (1941, 1976).

Although consideration must be given to the finding that fearless dominance differentiated the business sample from the criminal and noncriminal samples, elevation on this facet alone does not indicate psychopathy (Lilienfeld et al., 2012). The elevation of fearless dominance suggested that the business sample had a significant pattern of psychopathy traits and when coupled with higher levels of either or both disinhibition or meanness would suggest a psychopathic individual (Board \& 
Fritzon, 2005; Hall \& Benning, 2006; Hall et al., 2014; Lilienfeld et al., 2012; Skeem et al., 2011). Benning et al. (2018) suggest that fearlessness without deficits in cognitive or executive functioning may lead to social assertiveness, confidence, persuasiveness, and limited sensitivity to the feelings of others due to reduced personal responsivity to fear or anxiety. Hence, successful psychopathy may be characterised by high levels of fearless dominance/boldness, with moderate levels of self-centred impulsivity/disinhibition and coldheartedness/meanness.

The results relating to the criminal sample from the findings by Brooks (2017) provided support for Hare's (2003) research on psychopathy in offenders, as well as secondary psychopathy (Lykken, 1957; 1995). The results indicated a significant elevation in self-centred impulsivity in the criminal sample, although this elevation alone does not suggest a psychopathic individual. This appeared to reflect greater similarities with Factor 2 of the PCL-R, suggesting features of disinhibition, impulsivity, and recklessness. The elevation of self centred-impulsivity/disinhibition in the criminal sample suggested that criminal psychopathy may form a different profile, characterised by higher levels of disinhibition and moderate levels of boldness and/or meanness (Hall \& Benning, 2006; Hare, 2003; Lilienfeld et al., 2012). One limitations of the results relating to the criminal sample, is in determining whether the elevation in self-centred impulsivity captures a unique profile of psychopathy, associated with greater lifestyle and antisocial features, or alternatively is reflective of overarching features of antisocial personality disorder.

The findings also suggested that psychopathy traits in the community, shared a different profile compared to both the business and criminal samples. Terming this noncriminal psychopathy, Brooks (2017) contended that elevated levels of both fearless dominance/boldness and self-centred impulsivity/disinhibition captured this sample. The findings suggested that noncriminal psychopathy may be distinct from criminal and successful psychopathy, reflecting a pattern of boldness and disinhibition. Based on the CAPP model of psychopathy (Cooke et al., 2012), it is theorised that noncriminal and criminal psychopathy share similarities in the behavioural, cognitive and emotional domains, yet noncriminal psychopathy is marked by traits from the self and dominance domains. In relation to the triarchic model (Patrick et al., 2009), the results suggested that noncriminal psychopathy may be characterised by moderate to high levels of both boldness and disinhibition and 
low to moderate levels of meanness. This finding was further supported by the pattern in clinical levels of psychopathy based on $T$ scores of 65 and above on the PPI-R (Lilienfeld \& Widows, 2005).

The PPI-R manual describes fearless dominance as the perception of oneself as a risk taker, unafraid of physical danger, free of nervous habits and social anxiety, remaining cool under pressure, socially confident, charming and engaging, and verbally fluent and able to influence others (Lilienfeld \& Widows, 2005). In contrast self-centred impulsivity is depicted as seeing oneself as superior, being manipulative and exploitive, reckless and defiant of social norms, blaming, poor at problem solving, failing to consider consequences, and failing to learn from mistakes (Lilienfeld \& Widows, 2005). Interestingly, the Cleckley $(1941,1976)$ depiction of psychopathy appears to reflect a greater resemblance of fearless dominance characteristics, while Hare's psychopathy description, particularly factor two of the PCL-R, suggests an individual with greater self-centred impulsivity features. The results of the research indicated that both Cleckley and Hare's (2003) theories captured psychopathy, however, each theory described psychopathy in a specific population. Hare's psychopathy reflected criminal psychopathy, with some overlap with noncriminal psychopathy, while Cleckley's conceptualisation of psychopathy typified successful and noncriminal psychopathy. However, the results also provided support for the CAPP Concept Map and Triarchic Model, which appear to account for the differences across samples, serving as overarching theoretical models for conceptualising psychopathic personality. As the results failed to find a difference between the samples for coldheartedness, the researcher believed that it was likely that this trait shared overlap of varying degrees with both fearless dominance and selfcentred impulsivity across all populations (Patrick et al., 2009; Polaschek, 2015).

The results by Brooks (2017) are consistent with Lilienfeld et al. (2012) who found elevated levels of fearless dominance traits in USA presidents. The authors concluded that boldness/fearless dominance, but not disinhibition or meanness, was significantly positively associated with greater presidential leadership and performance ranking. It remained unclear in the findings by Lilienfeld et al. as to whether a cut-off point existed in which traits of boldness/fearless dominance became problematic and impeded performance. The observed results for the noncriminal and business samples also shared similarities with Board and Fritzon (2005) who observed 
elevated levels of histrionic, narcissistic and obsessive-compulsive personality traits in a sample of senior business managers. The findings by Brooks suggested that the business sample had greater levels of interpersonal-affective psychopathy features compared to the criminal and noncriminal samples, similar to factor one traits of the PCL-R (Hare, 2003) and resembling Cleckley's (1976) depiction of psychopathy. The marked elevation for this facet is of relevance to understanding successful psychopathy.

In the research by Brooks (2017), 17\% of the business sample was identified as having clinically elevated levels of fearless dominance. Clinically elevated levels are indicative of prototypical psychopathic traits, suggesting pathological significance (Lilienfeld \& Widows, 2005). The findings for the business sample are consistent with Howe et al. (2014) who found that 7 of 55 (12.7\%) financial investors had elevated levels of fearless dominance based on two standard deviations above the standardised mean score. Howe et al. suggested that boldness may serve as a positive adaptive psychopathy trait in moderate levels, leading to greater achievement (Dutton, 2012; Lilienfeld et al., 2012); yet in clinical levels was likely to be problematic and impair success. The number of participants with elevated traits of fearless dominance in both Brooks' and Howe et al.'s research has implications for the business sector. Psychopathic traits can lead to illegal and unethical business practices and have a toxic influence on colleagues and relationships (Boddy, 2011; Babiak \& Hare, 2006; Mathieu \& Babiak, 2016; Spector, 1997), however, it is unclear as to the extent to which fearless dominance/boldness may contribute to immoral and problematic behaviour. Brooks recommended that future research investigate differences in levels of psychopathy and success, determining whether subclinical levels may serve as a protective factor, while clinical levels may be deemed problematic (Gao \& Raine, 2010; Hall \& Benning, 2006; Mullins-Nelson et al., 2006).

\section{Conclusion}

Determining the presence of a pervasive personality pattern or disorder requires that the behaviour associated with a person's personality deviates from the normative expectations and is characterised by inflexibility, persistence, and results in distress or impairment (APA, 2013). Psychopathic personality is examined across a continuum; however, at moderate levels problems with integration, following rules 
and expectations, and reacting to concern are likely to be evident. At high levels, psychopathy will be pervasive and pathological, commonly causing significant distress to those associated with the person. There are many pathways to the development of psychopathy, including the dual and moderated pathways as discussed by Benning et al. (2018) and Hall and Benning (2006). These pathways provide an understanding as to why one individual may exhibit criminal psychopathy, yet another presents with psychopathy and reaches corporate success. According to Benning et al. (2018), fearlessness is pertinent feature of psychopathy and may differentiate forms of psychopathy when accompanied by either deficits or functionality in areas of cognitive and executive functioning. Successful psychopathy may be characterised by fearlessness and proficient cognitive and executive functioning, consistent with Ishikawa et al. (2011). Unsuccessful psychopathy, while being associated with fearlessness, is also related to deficits in cognitive and executive functioning. This form of psychopathy may also be further perpetuated by the experience of adverse events promoting social detachment, hostility, and distrust towards others (Benning et al., 2018).

It is evident that the manifestation of psychopathic traits has been found to vary across contexts and samples examining psychopathy, with differences observed between criminal and business samples (Board \& Fritzon, 2005; Brooks, 2017; Howe et al., 2014). While the difference between types of psychopathy can be identified at the trait level, there is a lack of research exploring behavioural and physiological differences between criminal and noncriminal psychopathy. There is need for studies examining the relationship between psychopathy traits, success, and physiological reactions in response to stress. This form of research may employ stress design paradigms measuring galvanic skin response to a stimuli similar to that employed by Hare (1966) and Ogloff and Wong (1990) with offender samples. Research on psychopathic traits and response to stress in a successful sample would provide a greater understanding as to whether fearlessness and boldness serve as adaptive traits in the community, or if successful psychopathy is associated with the same physiological markers or deficits that have been observed in studies on criminal psychopathy (Hare, 1966; Ishikawa et al., 2001). There has recently been a preliminary body of research emerging on behavioural outcomes of psychopathic personality in the workplace, such as work cohesion, leadership, bullying and 
performance (Babiak et al., 2010; Boddy, 2011; Lilienfeld et al., 2012; Mathieu \& Babiak, 2016), however, there remains several areas for further investigation. Additional outcomes to examine in relation to psychopathy, particularly noncriminal or successful psychopathy, include: annual income, accumulation of income, ability to maintain intimate relationships, engagement in risk taking behaviours, and preservation of friendships and family relationships (Benning et al., 2018; Jonason \& Kavanagh, 2010; Martens, 2014). Lastly, there is still contention regarding what constitutes successful or noncriminal psychopathy. For some time the point of differences was the absence of a criminal record, yet, this appears to be only a component of determining noncriminal psychopathy. The Clinical Classification Criteria of Psychopathy (CCCP) as discussed in chapter 2, specifies a range of criteria that can be applied to differentiating presentations of psychopathic personality. The CCCP classifies the capacity of a psychopathic person, attributing a classification of accomplished, unremarkable, criminally inclined or accomplished-criminally inclined. Implementing a specification criteria assists in assigning a level of capacity to a psychopathic individual, allowing for clear clinical determination of the relationship between a psychopathic person, competency and individual contextual factors. Although he CCCP is a proposed clinical framework and in need of further empirical analysis, without a process to operationalize or define noncriminal and criminal psychopathy, there will remain contention and confusion in relation to the 'threshold limit', the point whereby psychopathy can be considered criminally, noncriminally or even successfully inclined.

\section{References}

American Psychiatric Association. (2013). Diagnostic and statistical manual of mental disorders (5th ed.). Washington, DC: Author.

Babiak, P. (1995). When psychopaths go to work: A case study of an industrial psychopath. Applied Psychology: An International Review, 44, 171-188.

Babiak, P., \& Hare, R. D. (2006). Snakes in suits: When psychopaths go to work. New York: Harper Collins.

Babiak, P., Neumann, C. S., \& Hare, R. D. (2010). Corporate psychopathy: Talking the walk. Behavioural Sciences and the Law, 28, 174-193. doi: 10.1002/bsl.925 
Bar-On, R. (2008). Emotional quotient inventory: Higher education (EQ-i:HEd). North Tonawanda, NY: Multi-Health Systems.

Bechara, A., Damásio, A. R., Damásio, H., \& Anderson, S. W. (1994). Insensitivity to future consequences following damage to human prefrontal cortex. Cognition, 50, 7-15. doi: 10.1016/0010-0277(94)90018-3

Benning, S. D., Venables, N. C., \& Hall, J. R. (2018). Successful psychopathy. In C. J. Patrick (Ed.), Handbook of psychopathy ( $2^{\text {nd }}$ Ed.), (pp. 585-608): New York: Guilford Press.

Blair, R. J. R., Jones, L., Clark, F., \& Smith, M. (1997). The psychopathic individual: A lack of responsiveness to distress cues? Psychophysiology, 34, 192-198. doi: 10.1111/j.1469-8986.1997.tb02131.x

Blair, J., Mitchell, D., \& Blair, K. (2005). The Psychopath emotion and the brain. United Kingdom: Blackwell Publishing.

Board, B. J., \& Fritzon, K. (2005). Disordered personalities at work. Psychology, Crime \& Law, 11, 17-32. doi: 10.1080/10683160310001634304

Boddy, C. R (2011). Corporate psychopaths: Organisational destroyers. London: Palgrave Macmillian.

Boddy, C. R. (2015). Organisational psychopaths: A ten year update. Management Decisions, 53, 2407-2432. doi: 10.1108/MD-04-2015-0114

Book, A. S., Quinsey, V. L., Langford, D. (2007). Psychopathy and the perception of affect and vulnerability. Criminal Justice and Behavior, 34, 531-544. doi: $10.1177 / 0093854806293554$

Brook, M., \& Kosson, D. S. (2013). Impaired cognitive empathy in criminal psychopathy: Evidence from a laboratory measure of empathic accuracy. Journal of Abnormal Psychology, 122, 156-166. doi: 10.1037/a0030261

Brooks, N. (2017). Understanding the manifestation of psychopathic characteristics across populations. Doctoral Thesis, Bond University.

Cleckley, H. M. (1941). The mask of sanity: an attempt to reinterpret the so-called psychopathic personality.London: The C. V. Mosby Company.

Cleckley, H. M. (1976). The mask of sanity (5th ed.). St Louis: Mosby.

Cleckley, H. (1988). The mask of sanity: An attempt to clarify some issues about the so-called psychopathic personality(5th ed.). Augusta: E. S. Cleckley.

Cooke, D. J., Hart, S. D., Logan, C., \& Michie, C. (2012). Explicating the construct of psychopathy: Development and validation of a conceptual model, the comprehensive assessment of psychopathic personality (CAPP). International Journal of Forensic Mental Health, 11, 242-252. doi:

10.1080/14999013.2012.746759 
Cornell, D. G., Warren, J., Hawk, G., Stafford, G., Oram, G., \& Pine, D. (1996). Psychopathy in instrumental and reactive violent offenders. Journal of Consulting and Clinical Psychology, 64, 783-790. doi: 10.1037/0022006X.64.4.783

Costa, P. T., \& McCrae, R. R. (2003). Personality in adulthood: A five-factor theory perspective(2nd ed.). New York: Guilford Press.

Decety, J., Chen, C., Harenski, C., and Kiehl, K. A. (2013). An fMRI study of affective perspective taking individuals with psychopathy: imaging another in pain does not evoke empathy. Frontiers in Human Neuroscience, 7, 1-12. doi: $\quad$ 10.3389/fnhum.2013.00489

Diekhof, E., Kaps, L., Falkai, P., \& Gruber, O. (2012). The role of the human ventral triatum and the medial orbitofrontal cortex in the representation of reward magnitude: An activation likelihood estimation meta-analysis of neuroimaging studies of passive reward expectancy and outcome processing. Neuropsychologia, 50, 1252-1256. doi: 10.1016/j.neuropsychologia.2012.02.007

Douglas, K. S., Vincent, G. M., \& Edens, J. F. (2018). Risk for criminal recidivism: The role of psychopathy. In C. J. Patrick (Ed.), Handbook of psychopathy(2 ${ }^{\text {nd }}$ Ed.), (pp. 682-709): New York: Guilford Press.

Dutton, K. (2012). The Wisdom of psychopaths: What saints, spies, and serial killers can teach us about success. New York: Scientific American.

Fallon, J. (2014). The psychopath inside. New York: Penguin Group.

Fix, R. L., \& Fix, S. T. (2015). Trait psychopathy, emotional intelligence, and criminal thinking: Predicting illegal behavior among college students. International Journal of Law and Psychiatry, 42-43, 183-188. doi: 10.1016/j.ijlp.2015.08.024

Fowles, D .C., \& Dindo, L. (2009). Temperament and psychopathy: A dual-pathway model. Current Directions in Psychological Science, 18, 179-183. doi: 10.111/j.1467- 8721.2009.01632.x

Frick, P. J. (2006). Developmental pathways to conduct disorder. Child and Adolescent Psychiatric Clinics of North America, 15, 311-331. doi: 10.1016/j.chc.2005.11.003

Fritzon, K., Bailey, C., Croom, S., \& Brooks, N. (2016). Problematic personalities in the workplace: Development of the Corporate Personality Inventory. In P. Granhag, R. Bull, A. Shaboltas, \& E. Dozortseva (Eds.), Psychology and law in Europe: When West meets East. CRC Press. 
Gao, Y., \& Raine, A. (2010). Successful and unsuccessful psychopaths: A neurological model. Behavioral Sciences and the Law, 28, 194-210. doi: $10.1002 / \mathrm{bsl} .924$

Häkkänen-Nyholm, H., \& Hare, R. D. (2009). Psychopathy, homicide, and the courts: Working the system. Criminal Justice and Behavior, 36, 761-777. doi: 10.1177/0093854809336946

Hall, J. R., \& Benning, S. D. (2006). The "successful” psychopath: Adaptive and subclinical manifestations of psychopathy in the general population. In C. J. Patrick (Ed.), Handbook of psychopathy(pp. 459-478): New York: Guilford Press.

Hall, J. R., Drislane, 1. E., Patrick, C. J., Morano, M., Lilienfeld, S. O., \& Poythress, N. G. (2014). Development and validation of triarchic construct scales from the psychopathic personality inventory. Psychological Assessment, 26, 447461. doi: 10.1037/a0035665

Hare, R. D. (1966). Psychopathy and choice of immediate and delayed punishment. Journal of Abnormal Psychology 71, 25-29. doi: 10.1037/h0022909

Hare, R. D. (1999). Without conscience: The disturbing world of psychopaths among us. New York: Guilford Press.

Hare, R. D. (2003). The Hare Psychopathy Checklist - Revised (2nd ed.). Toronto: Mutli-Health Systems.

Hare, R. D., \& McPherson, L. M. (1984). Violent and aggressive behavior by criminal psychopaths.International Journal of Law and Psychiatry, 7, 35-50. doi: 10.1016/0160-2527(84)90005-0

Hare, R. D., \& Quinn, M. J. (1971). Psychopathy and autonomic conditioning. Journal of Abnormal Psychology, 77, 223-235.

Hart, S. D., \& Hare, R. D. (1996). Psychopathy and antisocial personality disorder. Current Opinion in Psychiatry, 9, 129-132.

Hickey, E. W. (2010). Serial murderers and their victims(5th ed.). Belmont, California: Wadsworth Cengage Learning.

Hickey, E. W., Walters, B. K., Drislane, L. E., Palumbo, I. M. \& Patrick, C. J. (2018). Deviance at its darkest: Serial murder and psychopathy. In C. J. Patrick (Ed.), Handbook of psychopathy( $2^{\text {nd }}$ Ed.), (pp. 570-584): New York: Guilford Press.

Howe, J., Falkenbach, D., Massey, C. (2014). The relationship among psychopathy, emotional intelligence, and professional success in finance. International Journal of Forensic Mental Health, 13, 337-347. doi: 10.1080/14999013.2014.951103

Ishikawa, S. S., Raine, A., Lencz, T., Bihrle, S., \& Lacasse, L. (2001). Autonomic stress reactivity and executive functioning in successful and unsuccessful 
psychopaths from the community. Journal of Abnormal Psychology, 110, 423-432. doi: 10.1037/0021- 843X.110.3.423

Johns J. H., \& Quay, H. C. (1962). The effect of social reward on verbal conditioning in psychopathic and neurotic military offenders. Journal of Consulting Psychology, 26,217-220

Jonason, P. K., \& Kavanagh, P. (2010). The dark side of love: Love styles and the dark triad. Personality and Individual Differences, 49, 606-610.

Karpman, B. (1941). On the need of separating psychopathy into two distinct clinical types: The symptomatic and the idiopathic. Journal of Criminal Psychopathology, 3, 112-137. Retrieved from http://psycnet.apa.org/psycinfo/1942-00202-001

Karpman, B. (1948). Conscience in the psychopath: Another version. American Journal of Orthopsychiatry, 18, 455-491. doi: 10.1111/j.19390025.1948.tb05109.x

Knight, K., Garner, B. R., Simpson, D. D., Morey, J. T., \& Flynn, P. M. (2006). An assessment for criminal thinking. Crime \& Delinquency, 52, 159-177. doi: $10.1177 / 0011128705281749$

Lilienfeld, S. O., Waldman, I. D., Landfield, K., Watts, A. L., Rubenzer, S., \& Faschingbauer, T. R. (2012). Fearless dominance and the U.S. presidency: Implications of psychopathic personality traits for successful and unsuccessful political leadership. Journal of Personality and Social Psychology, 103(3), 489-505. doi: 10.1037/a0029392

Lilienfeld, S. O., \& Widows, M. R. (2005). Psychopathic Personality InventoryRevised (PPI-R) professional manual. Florida: Psychological Assessment Resources.

Logan, M. H., \& Hare, R. D. (2008). Criminal psychopathy: An introduction for police. In M. St-Yves \& M. Tanguay (Eds.), Psychology of criminal investigation: The search for the truth(pp. 359-405). Cowansville, Quebec: Editions Yvon Blais.

Lykken, D. T. (1957). A study of anxiety in the sociopathic personality. Journal of Abnormal and Clinical Psychology, 55, 6-10. doi: 10.1037/h0047232

Lykken, D. T. (1995). The antisocial personalities. New Jersey: Erlbaum.

Mahmut, M. K., Homewood, J., \& Stevenson, R. J. (2008). The characteristics of non-criminals with high psychopathy traits: Are they similar to criminal psychopaths?. Journal of Research in Personality, 42, 679-692. doi: 10.1016/j.jrp.207.09.002

Martnes, W. J. H. (2014, October 7). The hidden suffering of the psychopath. Psychiatric Times. Retrieved from 
https://www.psychiatrictimes.com/psychotic-affective-disorders/hiddensuffering-psychopath

Mathieu, C., \& Babiak, P. (2016). Corporate psychopathy and abusive supervision:

Their influence on employees' job satisfaction and turnover intentions.

Personality and Individual Differences, 91, 102-106. doi:

10.1016/j.paid.2015.12.002

Mayer, J. D., Salovey, P., \& Caruso, D. R. (2002). Mayer-Salovey-Caruso Emotional Intelligence Test (MSCEIT) user's manual. Toronto: Multi-Health Systems.

McCoy, K., Fremouw, W., Tyner, E., Clegg, C., Johansson-Love, J., \& Strunk, J. (2006). Criminal-thinking styles and illegal behaviour among college students: Validation of the PICTS. Journal of Forensic Science, 51, 11741177. doi: 10.1111/j.1556-4029.2006.00216.x

McNab, A., \& Dutton, K. (2014). The Good Psychopath's Guide to Success: Bantam Press.

Mehrabian, A., \& Epstein, N. (1972). A measure of emotional empathy. Journal of Personality, 40, 525-543. doi: 10.1111/j.1467-6494.1972.tb00078.x

Meloy, J. R. (2005). Violent attachments. Oxford: Roman \& Littlefield.

Meloy, J. R., \& Shiva, A. (2007). A psychoanalytic view of the psychopath. In A. Felthous \& H. Sass. (Eds.). International handbook on psychopathic disorders and the law: Laws and policies (Vol. 1, pp.335-346). England Wiley \& Sons.

Millon, T., \& Davis, R. D. (1998). Ten subtypes of psychopathy. In T. Millon, E. Simonsen, M. Birket-Smith, \& R. Davis (Eds.), Psychopathy: Antisocial, criminal, and violent behaviour (p. 161-170). New York: Guilford Press.

Mitchell, D. G. V., Colledge, E., Leonard, A., \& Blair, R. J. R. (2002). Risky decisions and response reversal: Is there evidence of orbitofrontal cortex dysfunction in psychopathic individuals? Neuropsychologist, 40, 2013-2022. Retrieved from

http://citeseerx.ist.psu.edu/viewdoc/download?doi=10.1.1.455.3494\&rep=rep1 $\underline{\text { \&type }}=\mathrm{pdf}$

Morrison, D., \& Gilbert, P. (2001). Social rank, shame and anger in primary and secondary psychopaths. The Journal of Forensic Psychiatry, 12, 330-356. doi: $10.1080 / 09585180110056867$

Mullins-Nelson, J. L., Salekin, R. T., \& Leistico, A. M. (2006). Psychopathy, empathy, and perspective-taking ability in a community sample: Implications for the successful psychopathy concept. International Journal of Forensic Mental Health, 5, 133-149. doi: 10.1080/14999013.2006.10471238 
Mullins-Sweatt, S. N., Glover, N. G., Derefinko, K. J., Miller, J. D., \& Widiger, T. A. (2010). The search for the successful psychopath. Journal of Research in Personality, 44(4), 554-558. doi: http://dx.doi.org/10.1016/j.jrp.2010.05.010

Nelson, H. E. (1991). National adult reading test (NART): Test manual. Windsor: NFER-Nelson.

Ogloff, J. R., \& Wong, S. (1990). Electrodermal and cardiovascular evidence of a coping response in psychopaths. Criminal Justice and Behavior, 17, 231245. doi: $\quad 10.1177 / 0093854890017002006$

Patrick, C. J., Fowles, D. C., \& Krueger, R. F. (2009). Triarchic conceptualizations of psychopathy: Developmental origins of disinhibition, boldness, and meanness. Development and Psychopathology, 21, 913-938. doi: 10.1017/S0954579409000492

Paulhus, D.L., Hemphill, J. F., \& Hare, R.D. (in press). Manual for the Self-Report Psychopathy scale. Toronto: Multi-Health Systems

Perri, F. S. (2013). Visionaries or false prophets. Journal of Contemporary Criminal Justice, 29, 331-350. doi: 10.1177/1043986213496008

Polaschek, D. L. L., (2015). (Mis)understanding psychopathy: Consequences for policy and practice with offenders. Psychiatry, Psychology and Law. Advanced online publication. doi: 10.1080/13218719.2014.960033

Porter, S., Birt, A. R., \& Boer, D. P. (2001). Investigations of the criminal and conditional release profiles of Canadian federal offenders as a function psychopathy and age. Law and Human Behavior, 25, 647-661.

Porter, S., ten Brinke, L., \& Wilson, K. (2009). Crime profiles and conditional release performance of psychopathic and non-psychopathic sexual offenders. Legal and Criminological Psychology, 14,109-118. doi:

10.1348/135532508X284310

Poythress, N. G., Lilienfeld, S. O., Skeem, J. L., Douglas, K. S., Edens, J. F., Epstein, M., \& Patrick, C. J. (2010). Using the PCL-R to help estimate the validity of two self-report measures of psychopathy with offenders. Assessment, 17, 206-219. doi: 10.1177/1073191109351715

Reitan, R. M. (1992). Trail Making Test: Manual for administration and scoring. Tucson: Reitan Neuropsychology Laboratory.

Serin, R. C., \& Amos, N. L. (1995). The role of psychopathy in the assessment of dangerousness.International Journal of Law and Psychiatry, 18, 231-238.

Skeem, J. L., Polaschek, D. L. L., Patrick, C. J., Lilienfeld, S. O. (2011). Psychopathic personality: Bridging the gap between scientific evidence and public policy. Psychological Science in Public Interest, 12, 95-162.

doi:10.1177/1529100611426706 
Spector, P. E. (1997). Job satisfaction: Application, assessment, causes and consequences. Thousand Oaks, CA: Sage Publications.

Stevens, G. W., Deuling, J. K., \& Armenakis, A. (2012). Successful psychopaths: Are they unethical decision-makers and why? Journal of Business Ethics, 105, 139-149. doi: 10.1007/s10551-011-0963-1

Stone, M. H. (2001). Serial sexual homicide: Biological, psychological, and sociological aspects. Journal of Personality Disorders, 15, 1-18.

Stone, M. H. (2009). The anatomy of evil. New York: Prometheus Books.

Watt, B., \& Brooks, N. (2012). Self-report psychopathy in an Australian community sample. Psychiatry, Psychology and Law, 19, 389-401. doi: $10.1080 / 13218719.2011 .585130$

Williamson, S. E., Harpur, T. J., Hare, R. D. (1991). Abnormal processing of affective words by psychopaths.Psychophysiology, 28, 260-273. doi: 10.1111/j.14698986.1991.tb02192

Willemsen, J., \& Verhaeghe, P. (2012). Psychopathy and internalising psychopathology. International Journal of Law and Psychiatry, 35, 269-275, doi: $\quad$ 10.1016/j.ijlp.2012.04.004

Woodworth, M., \& Porter, S. (2002). In cold blood: Characteristics of criminal homicides as a function of psychopathy. Journal of Abnormal Psychology, 111, 436-445. doi: 10.1037//0021-843X.111.3.436 